\title{
A CIDADE DE NOSSAS AVÓS: A CONDIÇÃO DA MULHER EM PORTO ALEGRE/RS
}

\author{
Thaís da Silva Vieira ${ }^{1}$ \\ Ana Luiza Carvalho da Rocha (Orientação) \\ "A importância da cidade se faz sentir nas lembranças \\ não como uma entidade em abstrato, mas como uma \\ experiência de vida". \\ Myriam Lins de Barros
}

\section{Introdução}

Quem anda hoje pelas ruas de Porto Alegre pode pensar que nada modificou. Em muitas ruínas escondem-se as memórias dos antigos habitantes da cidade. O enfoque deste trabalho está dirigido ao espaço urbano que as mulheres - mães e esposas - nas décadas de 30/40, habitavam, espaços que dizem respeito sobre a própria condição da mulher em relação à família, à sociedade, à própria cidade.

O primeiro ponto a ser tocado é a condição da mulher no Rio Grande do Sul, desde sua formação, através do relatos de cronistas sobre este Estado, mostrando a questão da honra para os gaúcho e sua implicância no modo de vida de seus habitantes. Em seguida, através da narrativa de duas informantes, moradoras de Porto Alegre, busco mostrar esta cidade sobre o prisma de sua trajetória social, gênero e geração.

Antes de apresentar o Rio Grande do Sul e sua história, introduzo aqui uma breve biografia das mulheres ${ }^{2}$ que constam neste trabalho:

a) Dona Heloísa, 94 anos, nasceu, criou-se e casou-se em Santa Bárbara do Sul/RS. Morava numa estância, "pra fora" como ela mesma diz. Estudou em Cruz Ata e Carazinho, onde tinham escolas mais próximas. $\mathrm{O}$ pai era estancieiro, mas ascendeu a funcionário público. Ela se casou em 1930, com um telegrafista viúvo, com três filhos, bem mais velho que ela. Ela criou os dois filhos mais velhos do marido e teve mais cinco filhos. Depois de casar, mudou-se para Palmeira das Missões/RS, onde o marido trabalhava. Eles moravam no correio. Depois, eles se mudaram para Iraí/RS, onde viveu 16 anos, Cruz Alta/RS e Porto Alegre/RS, onde vive até hoje na casa de uma filha.

b) Dona Augusta, 78 anos, nasceu no bairro Partenon, em Porto Alegre/RS, filha de uma espanhola e um português, dono de restaurante. Com a morte do pai, aos 26 dias de vida

\footnotetext{
${ }^{1}$ Bolsista Apoio Técnico CNPq - Graduada em Comunicação Social/Publicidade e Propaganda.

${ }^{2}$ Os nomes foram alterados para preservar a identidade das informantes.
} 
foi dada, por sua mãe, por questões financeiras, para a cunhada e o irmão criarem. Então, ela viveu, e vive até hoje, no bairro Floresta. A sua família de criação era de portugueses, donos de armazém. Casou com o marido que pertencia a uma família rica, italianos, donos de lojas de móveis. Do casamento, teve duas filhas. Hoje é separada do marido há dez anos (não legalmente) e vive com a filha mais nova em um apartamento, no mesmo bairro que viveu toda sua vida.

\section{As mulheres de nossa terra ${ }^{3}$}

Através dos relatos de Augusto de Saint-Hilaire sobre o Rio Grande do Sul, descobrimos duas personagens no cenário do século XIX: a esposa recatada da campanha, "escrava da casa", que se esconde dos homens, não dirige a palavra a eles; e as "damas da sociedade", mulher da cidade, que preza pela civilidade, que sai à rua e frequenta bailes. Ambas parecem viver em mundos opostos, mas, na verdade, elas existem sobre a condição da honra. A honra feminina que está ligada à pureza e ao controle da sexualidade.

A mulher está sempre a um passo de cair na imoralidade: Saint-Hilaire mostra em seus relatos as condições em que as índias eram tratadas, como animais despudorados. Neste sentido, para a mulher não cair em tentação, ela deve ficar em casa, guardando sua honra: "Assim, não apenas cumpre à mulher preservar a honra masculina, mantendo um papel de subalternidade e fragilidade ante sua ação e prerrogativa, numa sociedade guerreira e militarista em sua origem, como após a constituição das fronteiras gaúchas, e a delimitação de seu código ético-moral a partir do espaço familiar, cumpre a necessidade de enobrecer, com sua conduta social, a "pujança" do Rio Grande do Sul" (CARVALHO DA ROCHA, 1985, p. 259).

Desta forma, a mulher que fica em casa, resguarda sua honra, e a que pode ocupar espaços públicos, são aqueles que mantém sua "condição moral inalterada" (1985, p. 258), como as Igrejas e as Escolas. Isto fica bem ilustrado no livro "A mulher rio-grandense" de Andradina de Oliveira sobre a situação da mulher na sociedade gaúcha, o que se conclui: "Trata-se de educar a mulher para além de seu papel de esposa e mãe, como forma de garantir a defesa moral da sociedade gaúcha, de seus familiares e parentes, pais, maridos e filhos" (1985, p. 258).

Agora, neste cenário da pureza feminina, que vem desde a formação do Estado gaúcho, encontram-se dona Heloísa, desde 1906, na campanha gaúcha, e dona Augusta, desde

\footnotetext{
${ }^{3}$ Os levantamentos a seguir foram retirados do capítulo IV, da dissertação de mestrado de Ana Luiza Carvalho da Rocha, "A dialética do estranhamento: a reconstrução da identidade social de mulheres separadas em Porto Alegre/RS".
} 
1923, na capital rio-grandense. Através delas, pode-se ver a semelhança, respectivamente, entre a "escrava do lar" e a "dama da sociedade".

Dona Heloísa vem do interior Rio Grande do Sul, o pai era um pequeno proprietário de terra que ascende socialmente, tornando-se funcionário público. Cresceu num sítio, vende a mãe fazendo as lidas da casa. Foi à escola para saber ler e escrever: "A minha infância? Foi boa. A minha infância. A gente naquela época era muita segura. A gente não saía, não tinha assim liberdade, né. Era em casa. (...) Mas era um ensino muito bom, isso eu lhe garanto que era. Mas muito, muito diferente assim. A maneira de ensinar, muito diferente. Tudo... a gente tinha uma pilha de caderno, levava pra casa, fazer os trabalho de casa, levava aqueles, trazia outros. A professora corrigia, noutro dia devolvia pra gente, pegava os que gente tinha estudado em casa".

Dona Augusta, criadas pelos tios, donos de armazém, conta que nunca passou dificuldades. Também foi à escola, mas até o tempo certo para aprender o que importa a uma mulher: "Agora os pais não deixavam as filhas estudar muito. Era cozinhar, lavar, passar... tinha que aprender isso. (...) Ah, eu sai do colégio pra aprender a cozinhar e a cozinhar pra todo mundo".

O direito da mulher é ser alfabetizada, dentro ótica da manutenção da honra gaúcha, pois, como coloca dona Heloísa: "as meninas, eram criadas pra o casamento, pra ser esposa, mãe, dona de casa, porque cedo já começavam a aprender costurar, cozinhar, bordar as coisas assim, né, elas aprendiam. Muitas também não tinham grandes estudos mesmo, né, grande facilidade, a maioria era professora". Ou dona Augusta: "Minha filha, o que que eu ia fazer. Era hábito... quando me tiraram do... eu fiz o ginásio, depois me tiraram do colégio! "Não agora já tá pronta pra ir pra cozinha". Eu ia pra cozinha".

As profissões permitidas fora do lar eram as dentro dos espaços mantenedores da moral: "Porque na minha época mesmo, médica parece que não tinha não, eram só os homens, depois que as moças começaram a estudar medicina. Era, era professora, e eu adorava professora, era meu sonho dourado ser professora, sabe disso? E tinha uma facilidade pra aprender, impressionante. Eu já chegava a sonhar que eu tava lecionando, de tanto que eu tinha vontade de ser professora" (Dona Heloísa). "Faculdade não se pensava nisso. Eu tirei até o ginásio, tava tão bem, de... até, tinha até os meus diplomas e tudo, me saía tão bem. E até era... como é... enfermeira do meu grupo... com uma cruz vermelha assim no peito. Até dei pro meu netinho depois. E... mas... se ter profissão assim! Não" (Dona Augusta). 
É muito claro nas entrevistas uma condição de mulher, criada para ser dona do lar, mãe e esposa. Antes do casamento, a mulher só sai acompanhada, veste-se de forma diferente das mulheres casadas, vive sobre a vigilância constante da família, dos vizinhos, da sociedade e, talvez, dela própria: "Era muito diferente do que agora a mocidade agora, né. Namorado: tinha o namorado, o pai ou a tia ficavam do lado... sentado. Não deixavam sozinha. Nem iam ao cinema, numa... não mesmo! (...)Era uma vida... hoje em dia eu vejo as coisas assim: vejo uma moça foi... foi todo mundo num bar, depois do bar foram... dormir... foram aqui, foram ali. Hora que eu ia pensar nisso! Eu me casei virgem! Porque... não me deixavam... se ele ia se despedir no portão, o namorado, papai vinha junto, ou a titia vinha junto. Eu não podia ficar sozinha" (Dona Augusta).

Quanto às vestimentas, ambas tecem vários comentários, que deixam na imaginação o figurino da mulher rio-grandense: "As mulheres casadas era até o pé o vestido, e as moças meia perna assim pra baixo do joelho. Era uma coisa impressionante. E era bonito, os vestidos bem rodadinho. Eu gosto muito de vestido, isso até hoje". (Dona Heloísa). "E o vestido, o vestido mais comprido, não era minissaia, nem sabia o que que era isso (...)Todo mundo de chapéu! Cada chapéu que eu tinha, bonito. Tinha que ter uma coisa na cabeça. E luvas!". (Dona Augusta).

Dona Heloísa coloca bem didaticamente a condição das vestimentas da época: "Era uma montoeira de babado e de fofo. Que coisa, né. Se sentiam, vivam... Acho muito bonito. E ninguém sentia calor. Mas é... que coisa engraçada, os homens era manga comprida, não é, manga curta, deus o livre, se as mulher não usavam manga curta, porque os homens iam usar manga curta. Deus o livre. E shorts essas coisa, é coisa nova. Essa palavra que eu acho nem brasileira não é nem, português não é, isso é coisa que veio de lá, não sei da aonde" (Dona Heloísa).

Depois do casamento, a vigilância se volta para as lidas domésticas e o quanto esta mulher é boa mãe, esposa e dona de casa. Normalmente, são outras mulheres que fazem a avaliação do desempenho da "mulher de verdade": "minha sogra não gostava de mim... porque era de família pobre. Ela... morei três anos com ela... eu limpava o meu quarto e quando eu via ela tava dentro do quarto, passando a mão em tudo, pra ver se saía pó" (Dona Augusta). Ou ainda: "Eu quando fazia as coisas na minha sogra, um dia, o meu marido disse: "olha, a Augusta sabe fazer tainha recheada muito boa. A tia dela disse e tudo...", e um dia, meu sogro foi comprar a tainha... e trouxe (...) e eu fiz uma tainha. Tava uma coisa assim maravilhosa, no forno. A minha sogra não... nem pegou isso! Comeu uma comida que tinha... de jeito nenhum, "eu não estou com vontade". Porque não foi ela que fez". 
Dona Heloísa contou uma vez sobre as galinhas vivas que ela tinha comprado para assar futuramente. Uma das galinhas era muito magra, mas ela não tinha percebido. Quem lhe chamou a atenção para o fato foi sua sogra, cobrando dela que ela não sabia escolher, nem cuidar das galinhas que servem para alimentar seu filho.

Para encerrar este panorama da condição feminina no Rio Grande do Sul, mas mais precisamente em Porto Alegre, onde as entrevistadas vivem até hoje, vale a colocação de dona Heloísa sobre os papéis de cada um: "E ficavam a família em casa. O marido saía pra trabalhar, né. Trabalhava e... o homem tinha a obrigação de sustentar a sua família. Agora, depois foi com o desenvolvimento foi surgindo, né, pelo menos no lugar onde eu morava era poucas pessoas, moças, senhoras, que trabalhavam".

\section{A cidade sob a ótica feminina}

A necessidade de se construir imaginariamente esta Porto Alegre vista por Dona Heloísa e Dona Augusta vem para mostrar a própria condição feminina neste cenário urbano. E mais, mostra-se uma cidade que não está nos livros de história, que parecem palpáveis. Tem-se aqui, duas Porto Alegre, parecidas e diferentes.

Dona Heloísa, que veio do interior, convive com a Zona Norte da cidade, próximo à periferia, cenário que, na época de sua vinda (em torno das décadas de 30/40), estava em fase inicial de urbanização. Como ela mesma diz, ela Zona Norte era assim: "Aumentou muito a cidade, porque essa Assis Brasil, pra cá não era calçada, era uma poeiragem, uma coisarada. Eu acho, os calçamentos vinham até, não me lembro se era Volta do Guerino, por ali. Mas isso, tudo assim era muito... não era o que é hoje. A Assis Brasil hoje tá cheia de prédio, e a cidade vai embora. Isso não era. Era uns casebre, às vezes tinha, pedaço que não tinha nada. E ia embora. Hoje tá asfaltado, tá muito bonito. Mas não era asfaltado, pra cá esse pedaço. Pra Sertório ali, um barracéu tremendo. Ali era a Avenida dos Gaúchos. Era o nome dela. Era calçada com esses paralelepípedo, esses coisa assim. Mas era umas calçada afundando, tudo feio". Um cenário bastante semelhante ao que ela estava acostumada no interior, com a "poeirada" e "barracéu": "Se nós morava fora? Sim, era, era uma estanciazinha. Era do meu pai. Hoje não tem mais a casa, tem os campos. Mas era um lugar muito, bem pertinho de Santa Bárbara. Hoje, tá tudo asfaltado, dá pra ir a pé ali, é perto. Mas naquela época não era tão perto não. Faz muito tempo. Não havia, não havia asfalto, não havia calçamento, não havia estrada, tudo uma coisa terrível de poeira, então, as pessoas saíam voltavam coberta de pó. Era tudo assim". 
Dona Augusta vive (e viveu) em uma zona nobre da cidade, próximo ao Centro: o bairro Floresta. Como nasceu e cresceu na capital gaúcha, ela acompanhou as transformações de seu bairro, do mato ao asfalto: "Era mato, campo! E eu ia pro colégio, o colégio, eu descia para ir pro colégio, o guris atiravam carrapicho nos cabelos da gente... então a minha irmã vinha coberta assim, a minha outra irmã, e... era mato tinha que ir com os pés assim, passando, pra ir lá no Caminho Novo. (...) Ah, e ia no tambo também, de manhãa! Aonde eu morava agora é tudo casas e tudo, ali o campo, tinha o campo com tambo. E a titia pra me fortalecer, ela pegou e... botava um pouquinho de iodo dentro do copo e levava o copo comigo e eu tomava leite tirado da vaca".

Depois de casadas, dona Heloísa e dona Augusta acompanharam a Porto Alegre do Estado Novo. Dona Heloísa sempre mais em casa, colocando que não conhecia bem Porto Alegre, porque pouco saía, ficava mais cuidando das tarefas domésticas. Dona Augusta, frequentava muitos bailes, cinemas, teatros, mas sempre em companhia de alguém, dos pais e, depois, do marido.

Mesmo com vidas diferentes, ambas passaram pelos mesmos lugares, onde, através de seus relatos, parecem locais diferentes. Um exemplo disto é a Confeitaria Rocco, um prédio imponente, no centro da cidade, com estátuas masculinas, local dos chás da sociedade: "Ah, eu ia tomar café. Já era namorada dele, mas ia com mais outra pessoa. A gente ia comer cuca e tomar chá ou então café. A gente saía do... da matinê, MATINÊ, a gente não ia de noite. Matinê e a gente ia no Rocco. O Rocco é lá no... Olha, era tão bonito: tinha assim... uma mesa... um balcão todo de vidro, e as cucas tudo ali, e os homens tudo de gravatinha, os garçons, servindo a cuca e o café pra gente" (Dona Augusta).

Já para dona Heloísa, a Rocco era assim: "A Rocco... era uma confeitaria simples, não era assim como, não sei, hoje não tem mais eu acho. Era uma confeitaria... mas não tinha esse luxo, essas coisas que tem hoje. Era mais simples. Mas era muito famosa a Confeitaria Rocco. Tinha os, como é os, doces muito bom, tinha a... Confeitaria Rocco. De vez em quando ia comprar doces pras criança, ali passava, muito raro. (...) Eu pouco fui no Centro. Não ia muito, de vez em quando que eu passava por ali. Mas era bom, tinha grandes lojas que hoje não tem mais".

Porto Alegre também era o local de bailes, das festas de família, ponto em que ambas entrevistadas concordam: "Ia à baile também, mas baile de dançar um junto com o outro não era esse... esses bailes de agora que fica se sacudindo aí. Não! Era dançando um com o outro, assim direitinho" (Dona Augusta). "Tinha... tinha uma festa, que hoje onde quer tem uma dança, quer dançar, ali não, aquilo era programado: "olha, hoje tem um convidado, tem 
uma festa tem um baile lá em tal lugar”. Porque o clube às vezes dava baile uma vez por mês quando muito, mas eles faziam nos hotéis, faziam reuniões dançante, nas casas de família, então aquilo era programado. Não tinha, hoje não, hoje sai aí e já sai dançando" (Dona Heloísa).

Enquanto dona Heloísa, quando saía de casa, ia no colégios pegar os filhos ou fazer comprar para a casa; dona Augusta, acompanhava o marido no locais públicos que uma mulher pudesse frequentar: "Teatro Coliseu, que beleza! Ai, eu ficava encantada com aquele teatro. Ia toda de chapéu, toda arrumada. Pegava-se o bonde... a gente não, não ia sem... na Rua da Praia, sem chapéu e sem luva! Não. Tinha que ir bem chique!" (Dona Augusta). "Mas eu gostava de ir no Mercado. Era tudo à vontade, tudo espalhado, a gente chegava ali, aquelas banca, e não tinha cerimônia. (...) Naquele tempo não tinha tanta coisa, a gente ia no mercado mais barato, não tinha supermercado também. Quando eu vim pra cá não tinha. Essas coisa, essas novidade tudo, o progresso que trouxe. A gente ia no Mercado porque lá tinha tudo e era mais barato. A gente escolhia no Mercado Público. Erva pelo menos era uma maravilha, tomava chimarrão e ia comprar erva lá que a gente escolhia à vontade, as sacas de erva aberta, verdinha. Coisa mais linda. (...) Justamente a parada do bonde era bem em frente ao Mercado. A gente descia ali" (Dona Heloísa). "Vamos passear... e... hoje nós vamos no cinema e tudo", "Tá". Então, eu botava as meias, em primeiro lugar, porque mulher sem meia. Botava as meias pra... e pegava ela no colo, ia na cadeira de balanço, que tá na casa da minha filha, que eu criei elas... e fazia ela dormir primeiro pra depois ir trocar de roupa. Botar ela na cama, que a minha sogra não ficava com elas, em nada. Quem ficava era... ia buscar minha tia e ficava com a minha tia sentada pra não acordar" (Dona Augusta).

As festas religiosas, que existem até os dias de hoje, eram habitadas pelas duas senhoras, assim, como os bailes, o lugar de divertimento familiar: "Ah, a Festa do Divino era muito linda. A Festa do Divino eles vinham em casa com a bandeira. E visitavam as casas. Então, nós pegava a bandeira e deitava em cima da cama, bandeira, em todas as casas. Então uma... (Filha - Botava nas peças e tirava uma fitinha, cortava um pedacinho da fita, né?) Aí a gente cortava... Escondido! Não, não dá, não deixavam não! Tirava, inclusive guardava na bolsa (Filha - Ah, pra dar sorte.)" (Dona Augusta). "Era bem, bem divertida a festa de navegantes. Mas só uma vez eu fui ver, a chegada da santa no mar, no Guaíba, na ponte. Que tão bonito que era aqueles barquinhos, aquelas coisa tudo. E depois tinha festa, eu nem sei onde á hoje a festa que fazem. A festa da melancia que eu nem vejo falar mais, que era. Era, mas melancia, na festa dos Navegantes se reuniam pra comer melancia, não sei se era simpatia, se era alguma coisa, eu sei que era, até hoje nem vejo falar. A gente ouvia, 
porque não tinha televisão, era no rádio, que a gente ouvia a propaganda da Nossa Senhora dos Navegantes, tinha as melancia, tinha churrascada, coisarada, aquelas barraca, nem sei se tem hoje, parece que não tem, será que tem?" (Dona Heloísa).

\section{À guisa de conclusões}

Concluindo, a ótica da mulher, neste caso, aparece sobre estes dois prismas, de trajetórias sociais e estilos de vida distintos: "Porto Alegre não conheci muito, porque eu pouco saía, né. Era dona de casa. Naquele tempo era dona de casa mesmo, só fazia serviço caseiro. Eu saía pouco, né, mas Porto Alegre já era grande, uma cidade muito grande. Movimento já era muito grande" (Dona Heloísa). "Às vezes, eu conto pra elas coisas assim, como a gente passa o tempo. (...) depois que eu casei já melhorei. Melhorei assim, eu tinha de tudo, meu pai não deixava faltar nada, nem a titia, mas eu melhorei assim foi de vida, viajei bastante. E... andava muito bem" (Dona Augusta).

Mesmo assim, alguns ponto de convergência foram apontados, talvez porque digam respeito ao que diz Myriam Lins de Barros: "A construção da imagem da cidade realizada pela narrativa da memória, embora partindo de pontos de vista diferentes que dizem ao lugar social que o(a) narrador(a) ocupa e ocupou ao longo de sua trajetória de vida, acaba convergindo para alguns pontos comuns que permitem pensar o universo investigado como parte de uma geração que viveu situações sociais próprias e distintas de outras faixas etárias" (LINS DE BARROS, 1999, p. 45).

Fica aqui a questão de quem constrói quem: a história do Rio Grande do Sul, com sua noção de honra e de culto ao macho, criou esta condição feminina de pureza e controle do sexo, ou a forma como homens e mulheres vêem a cidade e agem nela acaba por construí-la em diferentes prismas? Talvez um se interdependa outro: homem sem cidade e cidade sem homem.

\section{REFERENCIAS}

ARIÈS, Philippe. "A família e a cidade" in: Família, Psicologia e Sociedade, FIGUEIRA, Sérvulo (org.).

LINS DE BARROS, Myriam M. “Autoridade e afeto”. Rio de Janeiro, Jorge Zahar Editor, 1987.

LINS DE BARROS, Myriam M. "A cidade dos velhos" in: Antropologia Urbana, VELHO, Gilberto (org.), Rio de Janeiro, Jorge Zahar Editor, 1999.

OLIVEIRA, Andradina de. "A mulher rio-grandense". Porto Alegre, Livraria Americana, 1907. 
ROCHA, Ana Luiza Carvalho da. "A dialética do estranhamento: a reconstrução da identidade social de mulheres separadas em Porto Alegre/RS". Dissertação de mestrado. Porto Alegre, 1985.

SAINT-HILAIRE, Augusto de. "Viagem ao Rio Grande do Sul". Porto Alegre, Globo, 1935.

VELHO, Gilberto. “Individualismo e Cultura”. Rio de Janeiro, Jorge Zahar Editor, 1999. 